\title{
Teaching practice of the course of Laser Principle and Application based on PBL mode
}

\section{Yongliang Li, Beibei Lv, Siqi Wang}

Yongliang Li, Beibei Lv, Siqi Wang, "Teaching practice of the course of Laser Principle and Application based on PBL mode," Proc. SPIE 10452, 14th Conference on Education and Training in Optics and Photonics: ETOP 2017, 104523E (16 August 2017); doi: 10.1117/12.2270970

Event: 14th Conference on Education and Training in Optics and Photonics, ETOP 2017, 2017, Hangzhou, China 


\title{
Teaching Practice of the Course of Laser Principle and
}

\section{Application Based on PBL Mode}

\section{Yongliang Li, ${ }^{a}$ Beibei Lv, ${ }^{\text {b }}$ Siqi Wang ${ }^{a}$}

${ }^{a}$ School of Optoelectronic Engineering, Changchun University of Science and Technology, Changchun 130022, China

${ }^{\mathrm{b}}$ College of Foreign Languages, Changchun University of Science and Technology, Changchun 130022, China

\begin{abstract}
The primary task of university education is to stimulate students' autonomic learning and cultivate students' creative thinking. This paper put to use problem based learning (PBL) teaching mode, to enable students master flexible knowledge as the goal, and a detailed analysis of the implementation method and concrete measures of PBL teaching reform in the course of Laser Principle and Application, then compared with the former teaching methods. From the feedback of students and teaching experience, we get good teaching effect and prove the feasibility of PBL teaching mode in practice.
\end{abstract}

Key Words: PBL mode, Teaching Practice, Course of Laser Principle and Application, Autonomic Learning, Question Discussion

Since the 20th century, the laser is another major invention following the atomic energy, computer, semiconductor of mankind. As soon as it appeared, the world changed a lot, it has been widely used in the military, aerospace, communications, industry, medicine, scientific research, etc. ${ }^{1-5}$ Science and technology is the first productivity, and laser technology is one of the important component. Therefore, it's particularly important to learn the course of Laser Principle and Application, as a teacher, we should to introduce advanced laser principles and acknowledges, and professional laser technology to students. However, due to the difficulty of the course content, it is hard for the students to master the teaching content required by the 
syllabus in the limited hours. Therefore, in the process of teaching, the PBL mode can stimulate the students to a certain extent and improve the learning efficiency. In the arrangement of teaching tasks, students can be assigned to groups to discuss in order to enhance their team spirit and cultivate their creative thinking.

\section{Comparative analysis of two teaching modes of LBL and PBL}

\subsection{LBL teaching mode}

In the traditional course of Laser Principle and Application, teachers usually use LBL (Lecture Based Learning) as the teaching mode which is teaching-based, teacher-centered. The advantage of this teaching method is teachers can teach basic theoretical knowledge and basic concepts systematically, impart a lot of knowledge which organized clearly and systematic in a short time. So LBL has mainly dominated classes. However, the disadvantage of it is the students have been forced to learn, resulting in the emphasis on imparting knowledge and neglecting the cultivation of quality and ability. Students have been in the passive state of being indoctrinated, unable to participate in the entire teaching environment actively which makes the thinking becomes inactive, depressed their enthusiasm, initiative and creativity of learning, and ultimately led to high scores and low abilities. This indoctrination mode will enable students to gradually lose interest in learning and slipped aside in the 
classroom. How to start from the teaching methods, change the teacher-centered mode to promote students' learning ability and methods will be a great challenge to the education administrators and teachers themselves.

\subsection{PBL teaching mode}

PBL is a kind of teaching mode which has been paid more and more attention by domestic and foreign educators in recent years. PBL (Problem-Based Learning) is a problem-centered learning or problem based learning mode, which was founded by the American neurology professor Howard Barrows in 1969 at McMaster University in Canada. It's a kind of new teaching mode which takes the problem as the core, the problem solving as the driving force, the group presentation, exhibition, discussion and communication as the means, stimulates the student to take the initiative to self-study, fosters the student innovative thinking as the main goal. ${ }^{6}$ It focus is on putting learning in a complex, meaningful problem context, by allowing learners to work together and discuss common issues to solve practical problems, so as to learn the scientific knowledge behind the problem, develop students' thinking ability, cultivate their innovative consciousness and cooperation spirit. ${ }^{7}$

The research on PBL abroad is mainly concentrated in four aspects: research on students' performance, research on students' attitudes, research on the acquisition and

application of meta-cognitive skills, research on influencing factors of PBL. ${ }^{8-11}$ In 
China, research on PBL is mainly carried out in the electronic commerce and medical-related areas, while for science and engineering disciplines is very few. ${ }^{12-15}$

PBL's basic elements as the following, With the problem as the starting point of learning, all the learning content is based on the problem as the main axis; The problem must be a "real world" unstructured problem that students may encounter in their future professional field, with no fixed solutions and processes; Emphasis on group cooperative learning and autonomous learning, less teaching;

Student-centered, students must assume the responsibility of learning; The role of teacher is to coach; Self-evaluation and group-evaluation should be done at the end of each problem solved and each unit finished. The PBL teaching method liberates the education teaching from the traditional "three centers"(teacher-centered, classroom-centered, textbook-centered), emphasizes the spirit of active inquiry and innovative practice, focus on the cultivation of students' lifelong knowledge and ability to learn. ${ }^{16-18}$

\section{The utilization of PBL in the course of Laser Principle and Application}

\subsection{The practical application of PBL teaching mode in the course}

PBL mode mainly encourages students to find problems, ask questions, discuss questions and solve problems. The setting of the problem indicates the direction for the students, the students' automatic participation and active learning is greatly 
improved, and meanwhile the discussion in the classroom has deepened students' understanding of knowledge and strengthened their application. The problem here is not only the focus of study, but also the aggregation of related disciplines.

In the second chapter Optical Resonant Cavity of the course Laser Principle and Application, which was given to the students of Optoelectronic Information Science and Engineering in 2014, we divided four classes 1402112-115 (a total of 110 people) into 11 groups. In order to make the students interested in the courses they have taken, they are asked a few questions before starting the course. The first question is what the role of the resonant cavity is; the students were excited at once and had different opinions. Some said that the resonator is mainly used for optical amplification, and some said it's used to control beam characteristic mode, after the discussion they get together their ideas, agreed to provide optical feedback and control the characteristics of intra-cavity oscillation beam. The second question is raised about the form of the optical resonant cavity, students answered a lot of resonant cavity types, such as parallel plane cavity, double concave spherical cavity, plane concave cavity, double convex spherical cavity, planar convex cavity, convex concave cavity, etc. Then the third question, what are the classification and elements of the resonant cavity? After a few minutes of discussion, the students watched a video about industrial laser processing, with great interest, although the video is only 4 minutes, but the enthusiasm of students is fully stimulated. According to the contents of the video, the 
expansion of this course began. From the role of the laser resonator to the structure form; from the categories of the resonant cavity to the design elements of the resonator, the students summed up each question, the teachers only supplements the their answers.

\subsection{Teaching Effects of PBL Teaching Method}

Through the PBL teaching classroom test, those students who usually don't listen to the teacher carefully participate in a heated discussion enthusiastically; sometimes they can raise questions, and began to think actively. The learning atmosphere of the whole class is unprecedentedly high, and the students' learning initiative is stimulated. In the collective discussion, because they are divided into several groups, and each member of the learning level is different, it can make best use of the advantages and bypass the disadvantages, the atmosphere in the classroom is pretty high. To a climax again and again. After class, a questionnaire survey was conducted among 110 students in the class; the main purpose of this survey is to investigate the students' cognition and acceptance of this teaching mode. Of the 110 questionnaires collected, 78 were 'Very satisfied', accounting for $70.9 \%$ of the total; 29 were 'Partially satisfied', accounting for $26.4 \%$ of the total number; only 3 people 'Not very satisfied', accounting for $2.7 \%$. From the survey, we found that the PBL teaching mode has played a very positive role in students' learning, greatly aroused the 
initiative of students so that students can be enthusiastically absorbed in learning.

\section{The Requirements of PBL Teaching Method for Teachers and Students}

As an open teaching mode, PBL has a high demand for teachers' quality and teaching skills, teachers are required to master the content of the course and the relevant discipline knowledge, and should have the ability to ask questions and solve problems, and to use the knowledge flexibly, strict logical thinking ability and good organization and management ability. Teachers should be good at stimulating the enthusiasm of the students, combining education with recreation, with the skills to control the rhythm of the classroom. In addition, teachers should be familiar with the syllabus and the ability of students, so as to plan the focus and difficulty of the study, develop a targeted discussion outline, prepare for the basic premise of PBL teaching mode.

In the meantime, the successful development of PBL teaching mode requires active cooperation of students, from the preparation of information, students need access to a large number of literature, and actively communicate with each other, work together to draw the best conclusion. This way of learning, the time and effort in the preparatory work will be much greater than the ordinary classroom learning, therefore, it is necessary for the students to have the initiative study consciousness, otherwise it is difficult to achieve the expected teaching effect and goal. As Chinese students receive long-term cramming education, form a certain dependence on the traditional 
educational model, lack of initiative to identify problems and solve problems, some students are only satisfied with get high scores, they may feel that PBL teaching mode reform is too time-consuming, this is also a kind of dependence on the previous teaching philosophy and learning methods. Therefore, students should start from their own to complete the role conversion, from passive learners into the masters of learning.

\section{Conclusions}

PBL teaching mode is also applicable to other similar science and technology courses. It is student-centered, problem-focused, and problem-solving as the goal. The new learning mode and teaching mode help to stimulate the students, cultivate their innovative thinking, cooperative ability and practical operation ability. It is an important way to improve the teachers' idea and method of education.

\section{References}

[1] Junnan Wang, Longyue Gao, Yongliang Li, Bin Liu, "Experimental research on laser interference micro/nano fabrication of hydrophobic modification of stent surface," Lasers Med Science. 32(1), 21056 (2016).

[2] Heming Chen, Xinyan Zhao, Principles and Applications of Laser, Publishing House of Electronics Industry, 2, 323-373(2013). 
[3] Xinghua Qu, Laser Principle and Application, Tianjin: China Machine Press (2008).

[4] Xiangyin Li, Mingyu Yao, Zhuo Li, Laser Technology and Application, Harbin: Harbin Institute of Technology Press (2004).

[5] Bingkun Zhou, et al, Principles of Laser, Beijing: National Defense of Industry Press, (2004).

[6] Lily, Yiping Xu, Donglan Zhuo, "Application of LBL combined with PBL in surgical clinical teaching," Researches in Medical Education. 6(2):148-149 (2007).

[7] Hong Shi, Zhijun Fu, Shiyao Chen, "From 'problem-based teaching' to 'problem-based learning'," Chinese Higher Medical Education (2009).

[8] Arne Tarnvik, "Revival of the case method: a way to retain student-centered learning in a post-PBL era," Medical Teacher. 5(3):65-69 (2007).

[9] Barrett T, "The problem-based learning process as finding and being in flow," Innovations in Education \& Teaching International. 47(2):165-174 (2010).

[10] Edens, K.M, "Preparing Problem Solvers for the 21st Century through Problem-Based Learning," College Teaching. 48(2):55-60 (2000).

[11] Vardi, I \& Ciccarelli, M, "Overcoming problems in problem-based learning: a trial of strategies in an undergraduate unit," Innovations in Education and Teaching International. 45(4), 345-354 (2008).

[12] Qiquan Zhong, Interpretation of basic education curriculum reform (Trial), Shanghai: East China Normal University Press, 35 (2001). 
[13] Zhengmiao Yu, Jing Chen, "Problems of PBL Teaching in Single Course," Journal of Shanxi Medical University (Preclinical Medical Education Edition). (5), 501-5 (2005).

[14] Rude Liu, "PBL Learning: A thought of teaching reform that embodies the thought of constructivism," Theory and Practice of Education. (5), 302-305 (2001).

[15] Huiqing $\mathrm{Wu}$, "The role and relationship between teachers and students in PBL," Research in Education Development. (4),389-391 (2003).

[16] Xiangling Kuang, "Application of PBL method in E-commerce Teaching," Research on Teaching. (5),420-422 (2006).

[17] Fenglin Tang, "Jiliang Shen, Problem-based Learning and Educational Reality in China ," Comparative Education Review. (1),73-77 (2005).

[18] Yong Li, Research on PBL theory under the background of new curriculum reform [D], Master Thesis of Nanjing Normal University (2005)

Author:

Yongliang Li Mainly engaged in college education, laser Technology and Application.

E-mail: liyongliang@,cust.edu.cn

Tel: +861375651 1028

Fax: +86043185582860 